\title{
Microarrays no carcinoma mamário: aspectos genéticos
}

\author{
Microarrays in breast cancer: genetic aspects
}

\author{
Karolline Coutinho Abreu ${ }^{1}$, Luiz Alberto Sobral Vieira Junior ${ }^{2}$
}

\begin{abstract}
Abreu KC, Vieira Junior LAS. Microarrays no carcinoma mamário: aspectos genéticos. Rev Med (São Paulo). 2010 abr.-jun.;89(2):101-5.

RESUMO: A análise de expressão gênica de tumores mamários vem despertando enorme interesse de pesquisadores nos últimos anos. Testes clínicos precisos, reprodutíveis e validados têm sido utilizados na avaliação prognóstica e preditiva de subgrupos específicos de pacientes.
\end{abstract}

DESCRITORES: Neoplasias mamárias/genética; Análise de sequência com séries de oligonucleotídeos; Testes genéticos; Prognóstico.

\section{INTRODUÇÃO}

Iternacionalmente, tem-se diagnosticado um aumento de incidência de câncer de mama em mulheres, principalmente nos Estados Unidos e países europeus ${ }^{1}$; são mais de 1.000 .000 de novos casos que serão diagnosticados em todo o mundo neste ano ${ }^{1}$. No Brasil, é a neoplasia feminina mais comum, sendo a segunda maior causa de mortes por câncer feminino; estima-se que aproximadamente 49.300 mulheres apresentarão a doença até o final deste ano, com aproximadamente 10000 óbitos $^{2}$.

Ressalta-se que o câncer de mama resulta da interação de fatores genéticos e estilo de vida, hábitos reprodutivos e meio ambiente. Como todos os cânceres de mama, têm origem genética; acredita-se que $90 \%$ a $95 \%$ deles sejam esporádicos (não-familiares) e sejam decorrentes de mutações somáticas que se verificam durante a vida, e que $5 \%$ a $10 \%$ sejam hereditários (familiares) devido à herança de uma mutação germinativa ao nascimento, que confere a essas mulheres suscetibilidade ao câncer de mama.

Mesmo diante de elevada incidência, tem-se presenciado uma melhora nas taxas de sobrevida em muitos países devido a uma encorajadora tendência de detecção precoce, aliada ao uso de novos recursos terapêuticos.

\footnotetext{
1. Médica Ginecologista e Obstetra; Mastologista; Programa de Residência Médica em Mastologia do Centro de Ciências da Saúde da Universidade Federal do Espírito Santo (UFES).

2. Médico Ginecologista e Obstetra; Mastologista; Professor de Ginecologia e Coordenador do Programa de Residência Médica em Mastologia do Centro de Ciências da Saúde da Universidade Federal do Espírito Santo (UFES); Doutor em Medicina pela Universidade Federal de São Paulo, UNIFESP.

Endereço para correspondência: Rua Des. João Manoel de Carvalho, n²12, apt 301, Ed. Le Corbusier, Barro Vermelho, Vitória ES, CEP: 29057630. e-mail: Karolline.abreu@bol.com.br
} 
E mesmo diante dos avanços na detecção precoce e na compreensão da biologia molecular dessa doença, muitos pacientes em estágios iniciais acabam apresentando doença recorrente póstratamento. Por outro lado, é sabido que a grande parte das pacientes submetidas à terapia adjuvante poderia sobreviver mesmo na sua ausência, ou seja, utiliza-se quimioterapia em pacientes que não precisam porque não se sabe ao certo quais têm micrometástases ocultas. Análise de metanálises de ensaios randomizados e vários estudos retrospectivos não controlados mostraram que cerca de $70 \%$ das mulheres sem comprometimento dos gânglios axilares estão vivas e livres de doença dez anos após a cirurgia sem nenhum tipo de tratamento adjuvante e, apesar disso, muitas delas o recebem ${ }^{3}$.

Os fatores prognósticos são relevantes para se prever resultados específicos em cada paciente e devem ser utilizados na seleção de tratamentos individualizados ${ }^{4}$.

O Status nodal axilar, por exemplo, é o mais importante parâmetro usado para definir classes de risco em pacientes com doença inicial, entretanto não consegue determinar o padrão de resposta alcançada diante dos atuais sistemas terapêuticos ${ }^{3}$.

A responsividade endócrina é um importante fator preditivo, bem estabelecido, e que pode avaliar a vulnerabilidade do tumor a endócrino-terapia.

O proto-oncogene Her2-neu quando amplificado ou hiper-expresso, situação observada em 15 a $20 \%$ dos carcinomas de mama, está relacionado a pior prognóstico. Estudos retrospectivos sobre o benefício da quimioterapia adjuvante mostraram uma redução na sobrevida livre de doença para pacientes que apresentavam hiper-expressão desse gene ${ }^{5}$.

$\mathrm{O}$ fato de conhecer os fatores preditivos de maior precisão auxiliaria na decisão frente aos diversos tipos de terapia, determinando condutas individualizadas mais eficientes, que pudessem causar impacto na taxa de sobrevida global, redução

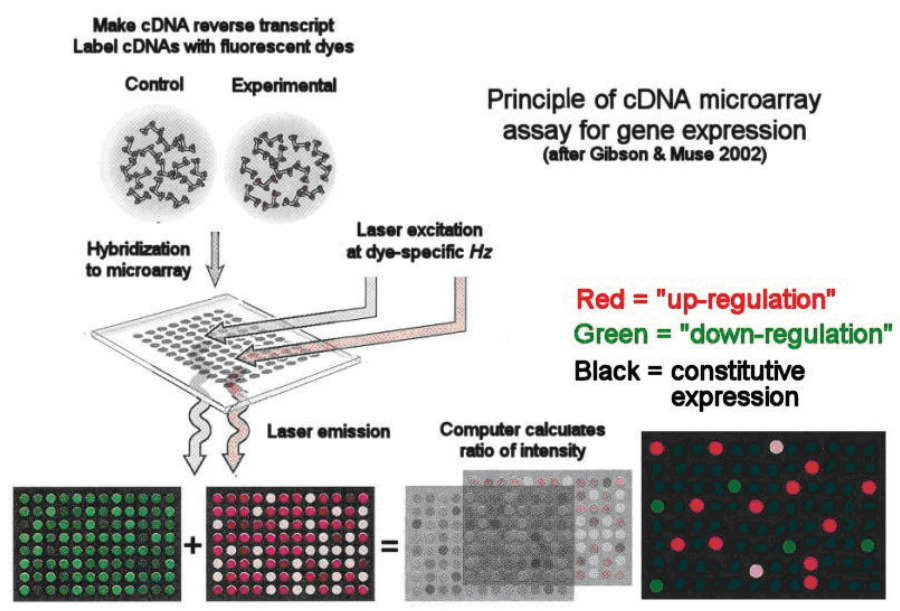

nos custos com assistência médica e melhoria na qualidade de vida dessas pacientes. E, ainda, pouparia muitos pacientes de terapias desnecessárias e, consequentemente, de seus efeitos deletérios.

Diante dos recentes avanços em biologia molecular, surge a possibilidade de codificação de perfis genéticos de tumores sólidos, relacionando-os a diferentes comportamentos clínicos e predizendo resposta a esquemas terapêuticos. De forma prática, criam-se "assinaturas" ou "impressões" genéticas que selecionam aqueles pacientes que mais se beneficiariam de determinada terapia.

E nesse preceito questiona-se: de que forma essas "assinaturas" poderiam facilitar a identificação de subtipos de câncer de mama?

\section{Bases genéticas}

Em 1953, a estrutura tridimensional da molécula de DNA - a dupla hélice - foi descoberta por Francis Crick, James Watson e Maurice Wilkins, quando trabalhavam em Cambridge, no Reino Unido. O resultado foi publicado em duas páginas da Revista Nature, em abril de 1953. Em 2003, 50 anos depois da descrição da dupla hélice, outro momento destacouse na comunidade científica: o sequenciamento do genoma humano ${ }^{6}$.

Avanços nas técnicas de biologia molecular têm possibilitado gerar uma vasta quantidade de dados, como as pesquisas com células-tronco, vacinas recombinantes e sequenciamento de vários genomas, por exemplo.

Os microarrays são micro-arranjos de DNA dispostos em um suporte sólido, geralmente um vidro especial, com tamanho semelhante a uma lâmina de microscópio óptico e que permite analisar um grande volume de dados simultaneamente, proporcionando a obtenção de um perfil da expressão gênica de um determinado tecido ${ }^{7}$.
Fonte: www.mun.ca/.../cDNA_microarray_ Assay_of_Gene_Expression.html.

FIGURA 1: Princípio de cDNA microarray análise da expressão gênica 
Um arranjo de DNA:

[...] consiste em um suporte sólido (lâmina de vidro ou membrana de nylon) no qual são fixados, de forma ordenada, fragmentos de DNA correspondentes aos genes que serão estudados (em geral obtidos de uma biblioteca de cDNA). Assim em cada ponto do arranjo existe cDNA ou oligonucleotídeo correspondente a um gene.

$\mathrm{Na}$ atualidade, as técnicas de microarrays possibilitam, entre outras coisas, a medição de "impressões genéticas" de células com câncer e a partir desses dados torna-se possível realizar análises, como a identificação de genes expressos em condições distintas, capazes de indicar potenciais genes a serem avaliados com maior detalhe a nível molecular.

\section{Testes validados}

Validade clínica define a capacidade de precisão e confiança de um determinado teste em identificar ou prever resultados finais e/ou intermediários de seu interesse.

Utilidade clínica define o equilíbrio entre benefícios e danos associados ao uso deste teste, na prática, incluindo o seu valor acrescentado para o manejo clínico e a tomadas de decisões comparado à sua não utilização ${ }^{8}$.

Alguns testes genéticos baseados na codificação genética de tumores de mama conseguiram comprovar sua capacidade em caracterizar diferentes grupos de pacientes e determinados comportamentos tumorais ${ }^{8}$.

O Oncotype DX tem como princípio o fato de que nem todas as pacientes se beneficiam igualmente da quimioterapia ${ }^{9,10}$. Constitui-se em um painel de 21 genes, através da técnica de RT - PCR, resultando em um score de recorrência de 0 a 100 . Deve ser utilizado nas pacientes com doença inicial, endócrinoresponsivas e linfonodo-negativas ou linfonodopositivas, porém na pós-menopausa.

O Score maior que 30 está relacionado a benefício significativo com a quimioterapia; de 18 a 30 sugere que não haverá benefício com a terapia, mas a decisão deve ser baseada na clínica; e Score inferior a 18 sugere mínimo benefício com o esquema terapêutico.

O MammaPrint é um micro-arranjo de DNA com base na atividade de 70 genes, fornecendo informações sobre a probabilidade de recorrência tumoral. O teste mede o nível de expressão de cada um desses genes em uma amostra de tecido de tumores tratados cirurgicamente, determinando se o paciente é considerado de baixo ou de alto risco para metástase à distância nos próximos 5 a 10 anos ${ }^{11}$.

As pacientes devem ter menos de 61 anos, estadio 1 ou 2 e linfonodos negativos, independente da expressão de receptores hormonais, para boa acurácia.

O Rotterdam Signature, desenvolvido pela Erasmus University Cancer Center em Rotterdam, é um teste prognóstico validado para pacientes linfonodo-negativos independente do status hormonal, e que se propõe a identificar grupos de pacientes com alto risco para recorrência a distância ${ }^{12}$.

O NuvoSelect ${ }^{\mathrm{TM}}$ (Nuvera Bioscience, Inc., Woburn, MA, EUA) utiliza um conjunto de 30 genes para predizer resposta completa a quimioterapia primária com paclitaxel, 5-fluouracil, doxorrubicina e ciclofosfamida (FAC+T) e um conjunto de 200 genes para predizer resposta tumoral após 5 anos de terapia endócrina ${ }^{13}$.

O ensaio H/l (HOXB13/ILI7BR) se baseia na identificação de 2 genes para predizer resposta à terapia com tamoxifeno em pacientes endócrinoresponsivos ${ }^{14}$. O IL17BR over expresso está relacionado a resultados favoráveis, enquanto a elevada expressão do gene HOXB se relaciona a doentes que apresentaram comportamento clínico mais agressivo, isto é, resistência ao tamoxifeno.

\section{Estudos clínicos}

\section{MINDACT BIG3-04}

O Breast International Group (BIG), em sua busca pela otimização do tratamento da neoplasia mamária, realizou um estudo prospectivo e randomizado comparando a assinatura de 70 genes com critérios clínico-patológicos na seleção do tratamento adjuvante de pacientes linfonodonegativos ou com até 3 linfonodos positivos.

Assim, o MINDACT ${ }^{5}$, estudo iniciado em fevereiro de 2007, avaliará o risco de 6000 mulheres através dos tradicionais fatores clínico-patológicos versus perfil de 70 genes (MammmaPrint $($ )). Se ambos os métodos de classificação revelarem o paciente com baixo risco de recidiva, quimioterapia adjuvante não será oferecida; se ambos os métodos de classificação revelarem alto risco de recorrência, quimioterapia será proposta; e se os métodos oferecerem resultados discordantes (estimado $32 \%$ dos doentes), o paciente será randomizado diante a avaliação isolada de cada método. Esperase que $10-20 \%$ das mulheres, que normalmente receberiam quimioterapia adjuvante baseada em seus fatores clínico-patológicos, sejam poupadas dessa terapia, sem qualquer impacto negativo na sua sobrevivência. 
A segundo aleatorização irá comparar esquemas diferentes de quimioterapias, com o objectivo de mostrar que um regime sem antraciclinas pode ser usado com eficácia similar ou superior e redução de efeitos colaterais, particularmente cardiotoxicidade e leucemia.

Uma terceira randomização incluirá todos os pacientes endócrino-responsivos pós-menopausais, comparando dois esquemas de terapia endócrina: 2 anos de tamoxifeno seguido de 5 anos de letrozol e 7 anos de letrozol iniciais. O MINDACT é o único estudo nesse sentido que irá fornecer dados que possam validar assinaturas genéticas preditivas.

O TRANSBIG também está criando um enorme banco de material biológico, composto por tecido tumoral fresco congelado, blocos de parafina e sangue / soro de todos os 6000 pacientes, que complementarem de maneira eficiente o estudo. Este biobank ficará sob a tutela do Comitê de Pesquisa da TRANSBIG e constituirá um recurso inestimável para o futuro da pesquisa do câncer de mama.

NSABP B-14 e B-20

Tanto o NSABP B-14 quanto o B-20 mostraram que o Oncotype $D X$ fornece resultados consistentes, reprodutíveis e precisos.

O NSABP B-14 testou 668 perfis genéticos de 675 tumores de pacientes previamente tratados com tamoxifeno ${ }^{9}$. Os níveis de expressão de 21 genes relacionados ao câncer foram definidos e aplicados em um algoritmo para calcular prospectivamente o risco de recidiva (baixo, intermediário ou alto) para cada paciente.

As proporções de pacientes classificados como tendo um baixo, intermediário ou alto risco pela RT-PCR assay foram 51,22 , e $27 \%$, respectivamente, e essa pontuação foi validada estatisticamente.

Já o NSABP B-20 objetivava avaliar o benefício da quimioterapia em relação a risco de recorrência à distância em pacientes endócrinoresponsivos e linfonodo-negativos tratados com tamoxifeno ${ }^{10}$.

Em um total de 651 pacientes, 227 mulheres receberam apenas tamoxifeno, enquanto para 424 foi acrescido tratamento quimioterápico (CMF). Observou-se que as pacientes com score igual ou superior 31 apresentavam uma substancial vantagem com a realização da quimioterapia, menor que 18 um benefício mínimo, e para scores entre 18 a 30 o benefício não estava bem definido. Esse estudo não só quantificou a probabilidade de recorrência, mas também o tamanho do benefício adquirido com a terapia.

\section{CONCLUSÃO}

Em todos os carcinomas mamários, principalmente na neoplasia inicial, o desafio de oferecer o regime terapêutico certo ao paciente certo é muitas vezes limitado pela incapacidade do médico de identificar subtipos específicos de respostas dentro do enorme número de pacientes acometidos. A terapia adjuvante, há tempos bem estabelecida, consegue reduzir o risco de recidiva à distância, entretanto a redução das taxas de mortalidade ainda é pequena.

Diversas estratégias têm sido desenvolvidas com o objetivo de identificar subgrupos mais homogêneos de pacientes, incluindo a utilização de informações prognósticas.

A identificação de grupos de pacientes prognosticamente distintos através da expressão gênica via microarray proporciona não só nos orientar quanto à abordagem terapêutica, mas também de que maneira selecionar quais terapias seriam mais eficazes nesses determinados subgrupos.

Evidências clínicas atuais nos orientam quanto ao fornecimento de aconselhamento científico para pacientes candidatos a análise genética, informando-os sobre os benefícios e prováveis danos relacionados a estes testes, bem como suas possibilidades em modificar o curso da doença.

Abreu KC, Vieira Junior LAS. Microarrays in breast cancer: genetic aspects. Rev Med (São Paulo). 2010 abr.-jun.;89(2):101-105.

\begin{abstract}
The analysis of gene expression in breast tumors has attracted great interest from researchers in recent years. Clinical tests accurate, reproducible and validated has been used to assess prognostic and predictive of specific subgroups of patients.
\end{abstract}

KEY WORDS: Breast neoplasms/genetics; Oligonucleotide array sequence analysis; Genetic testing; Prognosis. 


\section{REFERÊNCIAS}

1. Porter PL. Global trends in breast cancer incidence and mortality. Salud Publica Mex. 2009;51(Suppl. 2):s141-6.

2. Brasil. Ministério da Saúde. Instituto Nacional do Câncer. Estimativa 2010: incidência de câncer no Brasil. Rio de Janeiro: INCA; 2009. p. 29-30.

3. Benz C, Clark G, Conzen S, Dorn R, Fuqua S, Gralow $\mathrm{J}$, et al. Consensus statement: expedition inspiration fund for Breast Cancer Research Meeting 2002. Breast Cancer Res Treat. 2003;78(1):127-31.

4. Lonning PE. Breast cancer prognostication and prediction: are we making progress? An Oncol. 2007;18(Suppl 8):83-7.

5. Schippinger W, Dandachi N, Regitnig P, Hofmann G, Balic M, Neumann, R, et al. The predictive value of EGFR and HER-2/neu in tumor tissue and serum for response to anthracycline-based neoadjuvant chemotherapy of breast cancer. Am J Clin Pathol. 2007;128(4):630-7.

6. A descoberta do DNA e o projeto genoma. Rev Assoc Med Bras. 2005;51(1):1-1.

7. Mayer L. Tecnologia microarray (biochips de DNA). Webartigos; 2009 [cited 2009 Jun 21]. Available from: http://www.webartigos.com/articles/17028/1/tecnologiamicroarray-biochips-de-dna/pagina1.html.

8. EGAPP recommendation statement. Recommendations from the EGAPP Working Group: can tumor gene expression profiling improve outcomes in patients with breast cancer? Genet Med. 2009;11(1):66-73.

9. Paik S, Shak S, Tang G, Kim C, Baker J, Cronin M, et al.
A multigene assay to predict recurrence of tamoxifentreated, node-negative breast cancer. N Engl J Med. 2004;351(27):2817-26.

10. Paik S, Tang G, Shak S, Kim C, Baker J, Kim W, et al. Gene expression and benefit of chemotherapy in women with node-negative, estrogen-receptor-positive breast cancer. J Clin Oncol. 2006;24(23):3726-34.

11. van't Veer LJ, Dai $H$, van de Vijver MJ, He YD, Hart AA, Mao M, et al. Gene expression profiling predicts clinical outcome of breast cancer. Nature. 2002;415(6871):484-5.

12. Wang $Y$, Klijn JG, Zhang $Y$, Anieta M, Sieuwerts AM, Look MP, et al. Gene-expression profiles to predict distant metastasis of lymph-node-negative primary breast cancer. Lancet. 2005;365:671-9.

13. Ayers M, Symmans WF, Stec J, Damokosh Al, Clark E, Hess K, et al. Gene expression profiles predict complete pathologic response to neoadjuvant paclitaxel and fluorouracil, doxorubicin, and cyclophosphamide chemotherapy in breast cancer. J Clin Oncol. 2004;22(12):2284-93.

14. Ma XJ, Wang Z, Ryan PD, Isakoff SJ, Barmettler A, Fuller A, et al. A two-gene expression ratio predicts clinical outcome in breast cancer patients treated with tamoxifeno. Cancer. 2004;5(6):607-16.

15. Cardoso F, Piccart-Gebhart M, Van't Veer L, Rutgers E; TRANSBIG Consortium. The MINDACT trial: the first prospective clinical validation of a genomic tool. Mol Oncol. 2007;1(3):246-51.

Artigo recebido em: 03/06/2010

Artigo aceito em: 27/06/2010 